\title{
Review
}

\section{Acute Kidney Injury in COVID-19}

\author{
Marta Głowacka $\mathbb{D}^{\mathbb{D}}$, Sara Lipka, Ewelina Młynarska *(D), Beata Franczyk and Jacek Rysz
}

Department of Nephrology, Hypertension and Family Medicine, Medical University of Lodz, 90-549 Lodz, Poland; marta.glowacka96@gmail.com (M.G.); saralipka@wp.pl (S.L.);

bfranczyk-skora@wp.pl (B.F.); jacek.rysz@umed.lodz.pl (J.R.)

* Correspondence: emmlynarska@gmail.com; Tel.: +48-042-6393750

\section{check for}

updates

Citation: Głowacka, M.; Lipka, S.; Młynarska, E.; Franczyk, B.; Rysz, J. Acute Kidney Injury in COVID-19. Int. J. Mol. Sci. 2021, 22, 8081.

https://doi.org/10.3390/ijms22158081

Academic Editor: Hajime Nagasu

Received: 27 June 2021

Accepted: 21 July 2021

Published: 28 July 2021

Publisher's Note: MDPI stays neutral with regard to jurisdictional claims in published maps and institutional affiliations.

Copyright: (c) 2021 by the authors. Licensee MDPI, Basel, Switzerland. This article is an open access article distributed under the terms and conditions of the Creative Commons Attribution (CC BY) license (https:// creativecommons.org/licenses/by/ $4.0 /)$.

\begin{abstract}
COVID-19 is mainly considered a respiratory illness, but since SARS-CoV-2 uses the angiotensin converting enzyme 2 receptor (ACE2) to enter human cells, the kidney is also a target of the viral infection. Acute kidney injury (AKI) is the most alarming condition in COVID-19 patients. Recent studies have confirmed the direct entry of SARS-CoV-2 into the renal cells, namely podocytes and proximal tubular cells, but this is not the only pathomechanism of kidney damage. Hypovolemia, cytokine storm and collapsing glomerulopathy also play an important role. An increasing number of papers suggest a strong association between AKI development and higher mortality in COVID-19 patients, hence our interest in the matter. Although knowledge about the role of kidneys in SARS$\mathrm{CoV}-2$ infection is changing dynamically and is yet to be fully investigated, we present an insight into the possible pathomechanisms of AKI in COVID-19, its clinical features, risk factors, impact on hospitalization and possible ways for its management via renal replacement therapy.
\end{abstract}

Keywords: COVID-19; acute kidney injury; RRT; dialysis

\section{Introduction}

COVID-19 is an infectious disease caused by severe acute respiratory syndrome coronavirus 2 (SARS-CoV-2), and it originated in Wuhan, China, in December 2019. As of 4 March 2021, approximately 84,230,049 cases have been discovered worldwide, causing an ongoing global pandemic [1]. Such a large number of confirmed cases is related to the way the virus is transmitted, which is close human-to-human contact through droplets or aerosol via coughs, sneezes or talking. Infection may also occur by touching contaminated surfaces and then touching routes of transmission such as the mouth, eyes or nose [2]. COVID-19 disease mainly affects the respiratory system, which in more severe cases is manifested by pneumonia, hypoxemia and acute respiratory distress syndrome. Although the main focus is on the pulmonary features, physicians must be aware of complications that SARS-CoV-2 infection carries to other organs, including the kidneys [3]. Acute kidney injury (AKI) is the most common kidney manifestation among patients hospitalized with COVID-19. According to KDIGO, AKI is defined as any of the following: (1) an increase in serum creatinine (SCr) by $\geq 0.3 \mathrm{mg} / \mathrm{dL}(\geq 26.5 \mu \mathrm{mol} / \mathrm{L})$ within $48 \mathrm{~h}$; or (2) an increase in $\mathrm{SCr} \geq 1.5$ times of baseline within the prior 7 days; or (3) urine volume $<0.5 \mathrm{~mL} / \mathrm{kg} / \mathrm{hour}$ for $6 \mathrm{~h}$. AKI can be also staged for severity according to KDIGO: stage (1) increase in SCr to $1.5-1.9$ times baseline or by $\geq 0.3 \mathrm{mg} / \mathrm{dL}$; stage (2) increase $\mathrm{SCr}$ to $2.0-2.9$ times baseline; stage (3) increase SCr to 3.0 times baseline or increase in serum creatinine to $\geq 4.0 \mathrm{mg} / \mathrm{dL}$ ( $\geq 353.6 \mathrm{mmol} / \mathrm{L}$ ) or initiation of renal replacement therapy [4]. Moreover, AKI development is far more frequent in severe and critically ill patients and is associated with poor prognosis and higher mortality [5-7]. Therefore, understanding the underlying pathophysiology of kidney injury in the course of COVID-19 is crucial for early recognition of the damage and the implementation of optimal treatment. 


\section{Epidemiology}

With 84,230,049 cases of SARS-CoV-2 infection globally, at least one third is asymptomatic [8]. Among those COVID-19 patients who experience symptoms, about $80 \%$ develop mild to moderate symptoms, while $20 \%$ of cases present with severe symptoms over the course of the disease, of whom $6 \%$ become critically ill [9]. The overall mortality rate of COVID-19 patients is around 3\% but, in the critically ill group, it can reach 50\% [10].

The incidence of acute kidney injury in COVID-19 varies in different case reports. Studies in China $[5,10,11]$ have shown that AKI occurred in $5 \%$ to $29 \%$ within a median of 7-14 days after admission, whereas reports from the United States $[6,12,13]$ have shown greater rates reaching from $37 \%$ to $57 \%$ in COVID-19 positive patients. However, the onset of AKI in the US was observed much earlier-either upon admission or within $24 \mathrm{~h}$ of admission. Another study from Brazil also showed a high occurrence of AKI in 56\% of COVID-19 patients, of which $67 \%$ developed stage 3 AKI [14].

Fisher et al. [13] presented a comparison report between 3345 patients with COVID19 and 1265 patients without COVID-19 during the same hospitalization period. AKI development in the COVID-19 (+) group was higher than in the COVID-19 (-) group (57\% and $37 \%$, respectively), and a significant number of patients positive for COVID-19 had stage 3 AKI compared with patients negative for COVID-19 (17.2\% vs. 7.3\%). Moreover, $4.9 \%$ of the patients positive for COVID-19 required renal replacement therapy (RRT) compared with $1.6 \%$ of those negative for COVID-19. Other US studies reported RRT necessity in up to $19 \%$ of patients with COVID-19, while in Brazil it was up to $47 \%$ of patients.

The results of incidence of AKI in COVID-19 patients are presented in Table 1.

Table 1. Incidence of AKI in COVID-19 patients.

\begin{tabular}{|c|c|c|c|c|c|c|}
\hline & \multirow{2}{*}{ All Patients } & \multirow{2}{*}{ AKI } & \multicolumn{3}{|c|}{ Stages of AKI } & \multirow[t]{2}{*}{$\begin{array}{l}\text { RRT in Patients } \\
\text { with AKI }\end{array}$} \\
\hline & & & AKI 1 & AKI 2 & AKI 3 & \\
\hline Yang, X. [10] & 52 & $15(29 \%)$ & & & & \\
\hline Pei, G. [5] & 333 & $22(6.6 \%)$ & $4(18.2 \%)$ & $7(31.8 \%)$ & $11(50 \%)$ & \\
\hline Cheng, Y. [11] & 701 & $36(5.1 \%)$ & $13(1.9 \%)$ & $9(1.3 \%)$ & $14(2 \%)$ & \\
\hline Chan, L. [12] & 3993 & $1835(45.9 \%)$ & $387(21 \%)$ & $199(10.8 \%)$ & $491(26.7 \%)$ & $347(19 \%)$ \\
\hline Hirsch, J.S. [6] & 5449 & $1993(36.6 \%)$ & $927(46.5 \%)$ & 447 (22.4\%) & $619(31.1 \%)$ & $14.3 \%$ \\
\hline Fisher, M. [13] & 3345 & 1903 (56.9\%) & $942(49.5 \%)$ & $387(20.3 \%)$ & $574(30.2 \%)$ & $164(4.9 \%)$ \\
\hline Costa, R.L.D. [14] & 102 & $57(55.9 \%)$ & $10(17.5 \%)$ & $9(15.8 \%)$ & $38(66.7 \%)$ & $27(47.4 \%)$ \\
\hline Ferlicot, S. [15] & 47 & $1(2.2 \%)$ & $3(6.4 \%)$ & $2(4.3 \%)$ & $41(87.2 \%)$ & $30(63.8 \%)$ \\
\hline
\end{tabular}

\section{Mechanism of SARS-CoV-2 Cellular Kidney Infection}

It is now a well-known fact that the main target of SARS-CoV-2 is the lungs; more precisely, type II pneumocytes. More and more studies published to date have proved that not only the lungs are exposed to infection, but so are the heart, liver, gastrointestinal tract, bone marrow and kidneys $[3,16]$ Multiorgan tropism is due to the fact that SARS-CoV-2 gains access to the cells through an endogenous viral receptor angiotensin converting enzyme 2 (ACE2) [17].

In order for SARS-CoV-2 to enter the host, cells are required to bind its transmembrane spike (S) glycoprotein to cellular receptor ACE2. S consists of two subunits, each with a different function. $\mathrm{S} 1$ is responsible for binding to the host cell receptor, while S2 is used to fuse the viral membrane with the membrane of the infected cell $[18,19]$. Spike then requires proteolytic priming to be activated, which is granted by serine protease TMPRSS2. Therefore, ACE2 and TMPRSS co-expression is a key determinant for the entry of SARS-CoV-2 into host cells $[20,21]$. Once SARS-CoV-2 is in the cytosol of the 
infected cell, the translation of its RNA and virion synthesis begins. It has been proven that genomic replication and virion assembly occur within the double vesicles of the endoplasmic reticulum (ER) and the Golgi complex [22].

We can therefore conclude that susceptible kidney cells are those that express ACE2. Using RNA-Seq sequencing techniques, scientists were able to determine which kidney cell types comprised the ACE2 gene. The data show that ACE2 mRNA is mostly expressed in proximal tubular epithelial cells and podocytes [20,21]. This would concur with a report by Braun F. et al., who managed to isolate SARS-CoV-2 from epithelial cells of an autopsied kidney [23].

\section{Pathophysiology}

The best understood mechanism of kidney damage induced by SARS-CoV-2 is direct cellular infection. However, there are also few possible reasons for acute renal failure, such as inflammatory damage caused by cytokine storm, AKI related to acute respiratory distress syndrome (ARDS), kidney-lung crosstalk theory, hypovolemia and collapsing glomerulopathy [24-26].

\subsection{Direct Cellular Infection}

As mentioned before, SARS-CoV-2 penetrates through angiotensin converting enzyme 2. The highest concentration of ACE2 in the kidneys was proven to be located in proximal tubular epithelial cells and podocytes [20,21,27]. Therefore, the direct infection of kidney cells by SARS-CoV-2 virus is the most likely mechanism for the development of acute kidney injury. Autopsy data also speak to this mechanism of AKI because many researchers found virus-like particles in epithelial cells of kidneys [24].

\subsection{Cytokine Storm and AKI Related to ARDS}

The abnormal immune response associated with SARS-CoV-2 is also a likely mechanism for the development of acute renal failure. At the root of these irregularities lies the cytokine storm and leukopenia [24]. Sepsis, a hemophagocytic syndrome, can lead to a so-called "cytokine storm", which is a cytokine release syndrome (CRS). The most crucial cytokine responsible for this pathology is IL-6 [25]. IL-6 also occurs in ARDS complications of COVID-19. AKI in CRS is on intrarenal inflammation, increased vascular permeability, volume depletion and cardiomyopathy grounds. Cardiomyopathy can cause stasis in the renal veins, resulting in renal hypotension and hypoperfusion, leading to a reduction in the glomerular filtration rate. This phenomenon is called the syndrome type 1 , which is manifested by endothelial damage, pleural effusions, edema, intra-abdominal hypertension, third-space fluid loss, intravascular fluid depletion and hypotension [28]. Moreover, other complications of COVID-19, such as right and left ventricular failure, can cause AKI. The first one leads to blood stagnation in the kidneys, whereas the second one to reduced cardiac output and then to renal hypoperfusion [24]. There are five causes of AKI in ARDS: hemodynamic instability, hypoxemia/hypercapnia, acid-base dysregulation, inflammation and neurohormonal effects [25].

\subsection{Lung-Kidney Crosstalk Theory}

The occurrence of kidney dysfunctions in COVID-19 patients might be explained by the kidney-lung crosstalk theory. This is due to the increased concentration of cytokines in the blood, the release of which is promoted by lung injury. Elevated levels of cytokines, especially IL-6, cause an increase in alveolar capillary permeability and pulmonary hemorrhage, and may even lead to distant-end organ dysfunction as damage to vascular endothelium in the kidneys. As a consequence, it leads to secondary hypoxia of the kidney and further damage to its structures. In patients who did not have chronic kidney disease or AKI, the research has shown that most of them manifested ARDS and/or AKI after developing pneumonia, which also testifies to the presence of lung-kidney crosstalk [28]. 


\subsection{Hypovolemia}

An incorrect distribution of fluids, especially hypovolemia (a consequence of fever and tachypnea), may affect the kidneys. This condition causes renal hypoperfusion and, consequently, renal failure. Endothelial damage, loss of fluid into the third space and hypotension provoke renal hypoperfusion. Virus cells and cytokines produced by the organism destroy the endothelium, which causes edema, ascites and hydrothorax, which in turn leads to hypotension and a loss of fluids to the third space. The amount of circulating fluid is reduced and this damages the kidneys in the prerenal mechanism. [28] Many patients infected with SARS-CoV2 have gastrointestinal symptoms that greatly increase the loss of fluid and further dehydration of the patient, mainly leading to pre-renal AKI [25]. In hemodynamically unstable patients, the venous flow deteriorates. Rhabdomyolysis (a condition involving the rapid dissolution of damaged or injured skeletal muscle), metabolic acidosis (increased level of hydrogen ions in the systemic circulation, which results in a reduction in the level of serum bicarbonate) and hyperkalemia (serum or plasma potassium level greater than $5.0 \mathrm{mEq} / \mathrm{L}$ to $5.5 \mathrm{mEq} / \mathrm{L}$ ) are also associated with this condition. This has a significant impact on the degradation of kidney function and, later on, on the occurrence of AKI. [28] Therefore, optimizing hemodynamic is crucial to kidneys health.

\subsection{Collapsing Glomerulopathy}

Collapsing glomerulopathy (CG) is a histological term for focal segmental glomerulosclerosis defined by segmental or global glomerular collapse correlated with podocyte proliferation, whose typical feature is proteinuria. CG has been associated with various factors, but the essential one is the presence of Apolipoprotein 1 (APOL1) genotype, namely alleles G1 and G2 [29]. Since the COVID-19 outbreak, there have been several case reports presenting COVID-19 patients with CG, in which authors speculated about the possible mechanisms linking it to SARS-CoV-2 infection. Kissling et al. [30] suggested direct viral toxicity on tubular cells as a pathomechanism of acute tubular necrosis in COVID-19 patients with G1 variant of APOL1 gene, based on post-mortem kidney examination. In another report, Peleg et al. [31] failed to detect viral particles in kidney tissue; thus, cytokine storm was presumed as a cause of collapsing glomerulopathy in COVID-19 patients. Both theories are possible, especially with high-risk alleles of the APOL1 gene.

\section{Histopathology}

Many autopsies have been carried out since the beginning of the pandemic on COVID19 patients, especially in the search of complications the SARS-CoV-2 virus carries to the human cells. Histopathological examinations used, among others, light microscopy, electron microscopy and immunofluorescence.

COVID-19 patients with AKI rarely showed clinical symptoms. The kidneys were often atypical in macroscopic examination, sometimes enlarged. However, microscopic examination of the subjects showed acute tubular injury (ATI), tubulointerstitial injury and glomerular injury, but nevertheless mild in relation to the degree of AKI and blood creatinine concentration [15,32]. Other notable observations were: fibrosis, congestion of the glomeruli and periurethral capillaries and the presence of glomerular fibrin. In addition, changes in the kidneys included atherosclerosis, foci of ischemia, benign chronic glomerular and tubulointerstitial lesions. Moreover, microscopy revealed the presence of isometric vacuolization in the renal tubules as an important diagnostic point. These changes in COVID-19 patients confirm direct viral infection into cells as a mechanism of AKI. Moreover, they correlate with the presence of double-membrane-covered vesicles that contain vacuoles and may be an indicator of active SARS-CoV-2 infection [32,33].

Acute tubular injury (ATI) is the constant condition found in COVID-19 patients with AKI. ATI is characterized by the loss of the brush rim, degeneration of the vacuole, flattening of the lumen of the tubule, cellular inclusions as well as necrosis and detachment of the epithelium. These changes can be well observed in samples subjected to light microscopy. The presence of hemosiderin and fibrin in the renal tubules has been rarely 
observed [15,23,32]. However, no aggregated platelets were observed at all. Electron microscopy revealed corona-like virus-like cells in the proximal part of the renal tubules and in podocytes. Erythrocytes were present in the lumen of the periurethral vessels [23]. The footprint of interferon in capillaries in electron microscopy indicates a cytokine storm as a mechanism for kidney damage. The visible swelling of the endothelial cells is also evidence of damage to the endothelium [15]. The most frequent histological observations are presented in Table 2.

Table 2. The most common histopathological observations in COVID-19.

\begin{tabular}{|c|c|c|}
\hline Morphological Data & Nephron Segments & Pathophysiological Mechanism \\
\hline Epithelial necrosis & Proximal tubules & \multirow{2}{*}{$\begin{array}{l}\text { Direct viral infections, hemodynamic } \\
\text { disorders, rhabdomyolysis }\end{array}$} \\
\hline Cellular debris & Lumen of tubules & \\
\hline Myoglobin & Tubules & Rhabdomyolysis \\
\hline Corona-like viruses & Podocytes, tubules & \multirow{2}{*}{ Direct viral infections } \\
\hline Isometric vacuolization & Tubules & \\
\hline $\begin{array}{l}\text { Loss of brush border, } \\
\text { flattening, damage }\end{array}$ & Tubules & \multirow[t]{2}{*}{ Direct viral infections, cytokine storm } \\
\hline Swelling of endothelial cells & Glomerulus & \\
\hline
\end{tabular}

\section{Clinical Features}

As mentioned before, COVID-19 can be manifested as a mild or moderate infection or a severe or critical illness. Mild or moderate symptoms include cough, fever, fatigue, dyspnea and smell and taste loss. Severe COVID-19 cases additionally present with hypoxia and $>50 \%$ lung infiltration on imaging. The critical course of the disease includes respiratory failure, SIRS and/or multiple organ failure [9].

Although the main feature of COVID-19 is pneumonia, we focused our research on renal dysfunction. The most frequently reported disorder of the kidney was acute kidney injury (AKI). In researched studies $[5,6,11-13,16]$, the end point of AKI was defined by the "Kidney Disease: Improving Global Outcomes (KDIGO)" criteria explained above. These findings indicate that increase in serum creatinine in COVID-19 patients at admission can be a negative prognostic factor in AKI development. In addition, majority of patients who developed AKI presented with hematuria and proteinuria, although these were more frequent in severe or critically ill patients (Table 3).

Table 3. Laboratory data in AKI patients with COVID-19.

\begin{tabular}{|c|c|c|c|c|c|}
\hline & $\begin{array}{c}\text { Pei, G. [5] } \\
\quad n=35\end{array}$ & $\begin{array}{c}\text { Cheng, Y. [11] } \\
n=53\end{array}$ & $\begin{array}{c}\text { Chan, L. [12] } \\
n=656\end{array}$ & $\begin{array}{c}\text { Hirsch, J.S. [6] } \\
\quad n=1993\end{array}$ & $\begin{array}{c}\text { Li, Z. [34] } \\
n=147\end{array}$ \\
\hline Proteinuria & & & $84 \%$ & $26.0 \%$ & $88 / 147(60 \%)$ \\
\hline negative & $4 / 35(11.4 \%)$ & $16 / 53(30.2 \%)$ & & $168(26.0 \%)$ & $31(21 \%)$ \\
\hline+ & $24 / 35(68.6 \%)$ & $21 / 53(39.6 \%)$ & & $206(31.9 \%)$ & $39(27 \%)$ \\
\hline$++/+++$ & $7 / 35(20.0 \%)$ & $16 / 53(30.2 \%)$ & & $194(30.0 \%)$ & $15(10 \%)$ \\
\hline+++ & & & & $78(12.1 \%)$ & $3(2 \%)$ \\
\hline$p$ & 0.002 & $<0.001$ & & & \\
\hline Hematuria & & & $81 \%$ & $46.1 \%$ & $71 / 147(48 \%)$ \\
\hline negative & $14 / 35(40.0 \%)$ & $25 / 53(47.2 \%)$ & & $196(36.2 \%)$ & $21(14 \%)$ \\
\hline+ & $13 / 35(37.1 \%)$ & $16 / 53(30.2 \%)$ & & $96(17.7 \%)$ & $21(14 \%)$ \\
\hline
\end{tabular}


Table 3. Cont.

\begin{tabular}{|c|c|c|c|c|c|}
\hline & $\begin{array}{l}\text { Pei, G. [5] } \\
\quad n=35\end{array}$ & $\begin{array}{c}\text { Cheng, Y. [11] } \\
n=53\end{array}$ & $\begin{array}{l}\text { Chan, L. [12] } \\
n=656\end{array}$ & $\begin{array}{l}\text { Hirsch, J.S. [6] } \\
\quad n=1993\end{array}$ & $\begin{array}{c}\mathrm{Li}, \mathrm{Z} .[34] \\
n=147\end{array}$ \\
\hline$++/+++$ & $8 / 35(22.9 \%)$ & $12 / 53(22.6 \%)$ & & $148(27.3 \%)$ & $16(11 \%)$ \\
\hline+++ & & & & $102(18.8 \%)$ & $13(9 \%)$ \\
\hline$p$ & 0.007 & $<0.001$ & & & \\
\hline \multicolumn{6}{|l|}{ Serum creatinine } \\
\hline $\begin{array}{l}\text { Serum creatinine, } \\
\mathrm{mg} / \mathrm{dL}\end{array}$ & $0.79(0.64-0.95)$ & $1.49 \pm 0.44$ & $1.42(0.95-2.25)$ & $1.23(0.91,1.8)$ & $0.75(0.61-0.93)$ \\
\hline $\begin{array}{c}\text { Peak serum creatinine, } \\
\mathrm{mg} / \mathrm{dL}\end{array}$ & & $1.84 \pm 1.23$ & & $2.23(1.40,4.12)$ & \\
\hline \multicolumn{6}{|l|}{ Blood urea nitrogen } \\
\hline $\begin{array}{l}\text { Blood urea nitrogen, } \\
\mathrm{mg} / \mathrm{dL}\end{array}$ & $12.04(9.0-16.0)$ & $30.8 \pm 19.6$ & $31(18-51)$ & $23.0(14.75,37.0)$ & 0.01 \\
\hline
\end{tabular}

+—slight; ++—average; +++—significant.

More research is needed to determine whether the occurrence of AKI affects subsequent renal function. A study with a follow-up period of 3 weeks from the onset of the infection presented no improvement in kidney functions in 89.5\% of COVID-19 patients who developed AKI [5]. Another study shows that $46 \%$ of COVID-19 patients who had AKI at discharge did not recover to baseline serum creatinine levels [12]. Therefore, the assumption that AKI may lead to CKD is possible but needs further investigation.

\section{Risk Factors of AKI Development}

Most of the patients who experience the severe or critical course of COVID-19 have pre-existing conditions. The most common comorbidities are hypertension and other cardiovascular disorders, diabetes mellitus and obesity. They are considered to be the major risk factors for developing a more severe, if not critical, course of COVID-19 [35]. A meta-analysis by Henry and Lippi pointed out that patients with chronic kidney failure must also take precautions in exposure to SARS-CoV-2 virus, since CKD increases the risk of a severe course of the disease [36].

In our research, we focused on the variables that specifically led to AKI occurrence in COVID-19 patients. Hirsch et al. analyzed possible risk factors associated with AKI development which included older age, diabetes, hypertension, cardiovascular disease and respiratory failure, the last one being the most important factor [6]. In another study, there was an association between older age and male sex as a primary risk factors of developing AKI [13]. Thus, not only do comorbidities play a role in the incidence of AKI, but so do non-modifiable factors such as age and gender. The results of variable correlations with AKI development are presented in Table 4.

Furthermore, the issue of angiotensin-converting enzyme inhibitors (ACEI) and angiotensin-receptor blockers (ARB) in patients with COVID-19 infection and putative risk of AKI in COVID19 is worth addressing. The clinical use of ACEI and ARB was controversial at the beginning of the pandemic. Some researchers proposed, based on the mechanism of SARS-CoV-2 infection, that administering ACEI and ARB could aggravate the course of the disease. This speculation has been dismissed by several observational studies, as well as international societies such as The Council on Hypertension of the European Society of Cardiology. ACEI and ARB therapy should not be discontinued in the mild and/or moderate course of COVID-19 infection [37,38]. 
Table 4. The correlation between age, sex, comorbid conditions and AKI development.

\begin{tabular}{|c|c|c|c|c|}
\hline & Pei, G. [5] $n=19$ & Chan, L. [12] $n=1835$ & Hirsch, J.S. [6] $n=1993$ & Fisher, M. [13] $n=1903$ \\
\hline Age (years) & $64.0 \pm 8.1$ & $71(61-81)$ & $69.0(58.0,78.0)$ & $67.1(15.3)$ \\
\hline \multicolumn{5}{|l|}{ Sex $(\%)$} \\
\hline Men & $14(73.7)$ & & $1270(63.7)$ & $1091(57.3)$ \\
\hline Women & & $734(40)$ & & $812(42.7)$ \\
\hline Hypertension (\%) & $9(47.4)$ & $820(45)$ & $1292(64.8)$ & \\
\hline Diabetes mellitus (\%) & $8(42.1)$ & $568(31)$ & $830(41.6)$ & $569(29.9)$ \\
\hline Chronic kidney disease (\%) & & $339(18)$ & & $287(15.1)$ \\
\hline ACEI/ARB treatment history (\%) & $4(21.1)$ & & $655(32.9)$ & $195(10.2)$ \\
\hline Coronary artery disease (\%) & & & $289(14.5)$ & \\
\hline Congestive heart failure (\%) & & $244(13)$ & $208(10.4)$ & $87(4.6)$ \\
\hline Liver disease (\%) & & $99(5)$ & $42(2.1)$ & \\
\hline Peripheral vascular disease $(\%)$ & & 194(11) & $61(3.1)$ & \\
\hline Cancer (\%) & & & $133(6.7)$ & $38(2.0)$ \\
\hline Obesity (\%) & & & 739 (37.1) & \\
\hline
\end{tabular}

\section{Impact of AKI Development on Hospitalization and Mortality Rate}

In order to assess the impact of AKI development in patients with COVID-19 on the course of hospitalization and mortality rate, we have compiled the data from five different case reports and compared AKI patients with patients without AKI (Figures 1-3). The occurrence of AKI in COVID-19-positive patients resulted in a significantly increased number of admissions to the intensive care unit (ICU) in comparison to COVID-19 patients without AKI. In the same group of patients, the need for mechanical ventilation was also more noticeable. What stands out the most in our sheet is the fatality rate, which ranges from $33.3 \%$ up to $86.4 \%$ in COVID-19 patients with AKI in comparison to COVID-19 patients without AKI, which varies from $5.6 \%$ to $9.3 \%$. Therefore, patients with COVID-19 who develop AKI are at significantly higher risk of severe or critical course of the disease, respiratory failure and consequent mechanical ventilation. Moreover, AKI incidence undeniably increases the mortality rate in COVID-19 patients.

\section{ICU Admission}

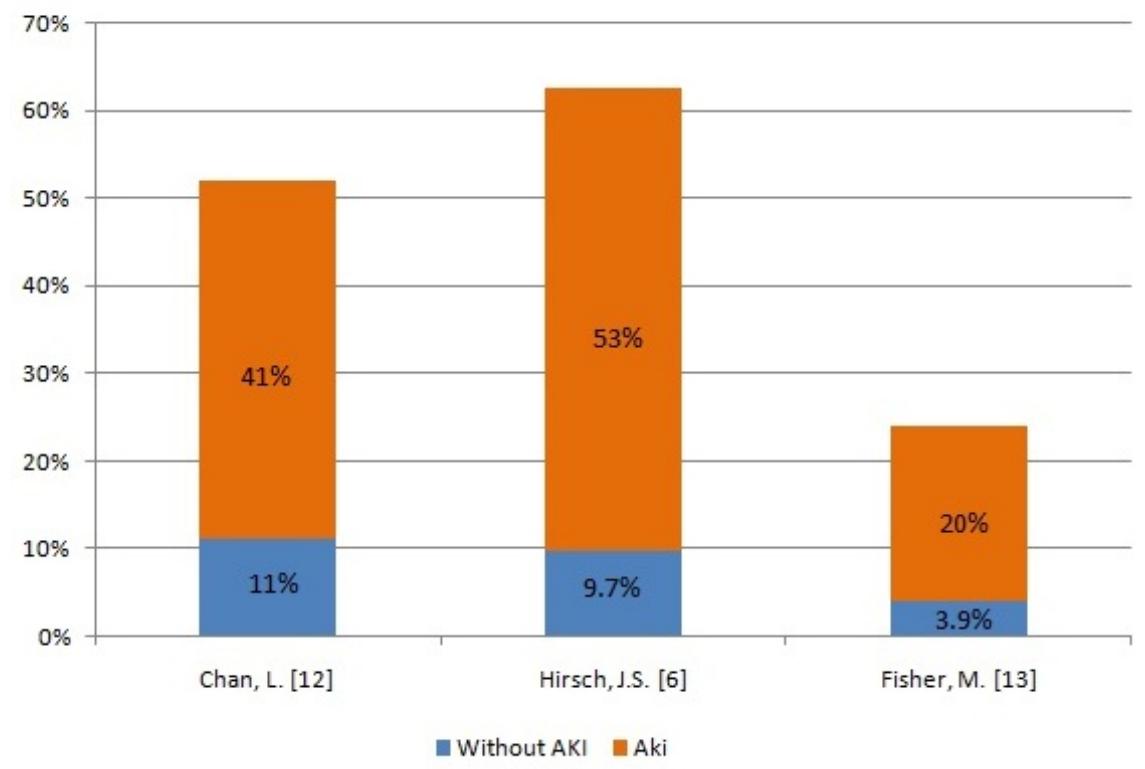

Figure 1. Intensive care unit admission in patients with AKI and no AKI $[6,12,13]$. 


\section{Mechanical ventilation}

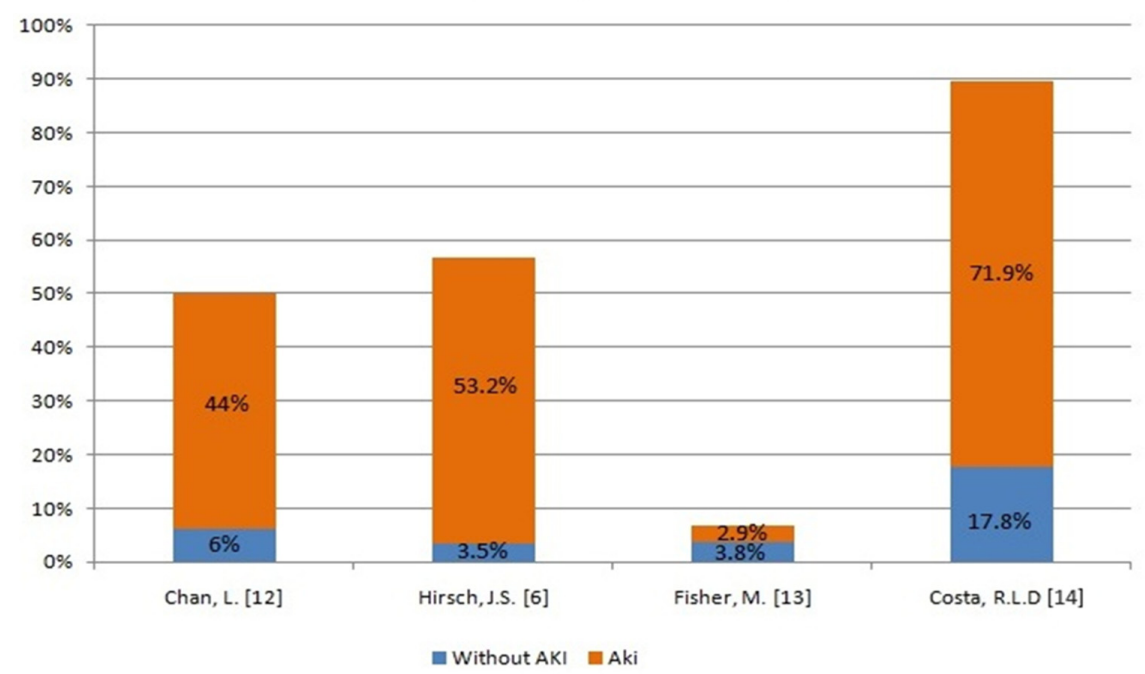

Figure 2. The need for mechanical ventilation in patients with AKI and no AKI [6,12-14].

\section{In-hospital death}

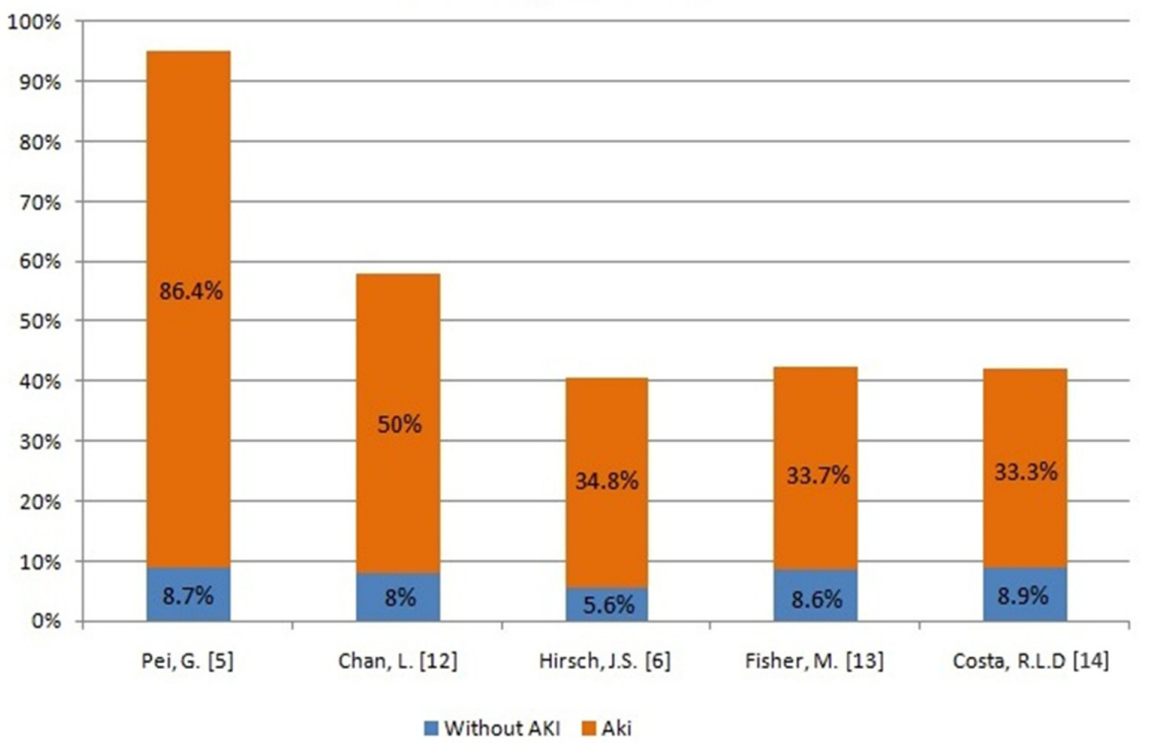

Figure 3. In-hospital death in patients with AKI and no AKI [5,6,12-14].

\section{Clinical Handling}

There is no specific treatment for AKI caused by COVID-19, and it has to be based on KDIGO and other guidelines. Prevention of AKI mainly consists of individual fluid therapies (balanced crystalloids), discontinuation or reduction in nephrotoxic drugs and, in the case of hypovolemia, the use of vasopressors. It is important to monitor kidney function with laboratory tests such as serum creatinine and urea levels.

Treatment should be systemic. We use antiviral drugs, antibiotics, corticosteroids, renin-angiotensin inhibitors, statins and anticoagulants. Drug therapy reduces the risk of developing AKI and causes a milder disease course [39].

\section{Renal Replacement Therapy}

Renal replacement therapy (RRT) is needed in up to $64 \%$ of critically ill COVID-19 patients who develop AKI (Table 1) [6,12-15]. It is due to abnormal concentrations of electrolytes and volume overload resistance to pharmacological treatment. The earliest studies suggested that, in hemodynamically unstable patients with COVID-19, the recommended 
approach was continuous RRT (CRRT) [28]. However, clinicians observed a significantly increased incidence of circuit clotting in COVID-19 patients, leading to prolonged time of treatment, as well as the unnecessary use of resources [24,40]. Therefore, we must take caution in choosing the most safe and effective strategy.

Ramirez-Sandoval, J.C. et al. [41] reported the viability and safety of prolonged intermittent renal replacement therapy (PIRRT) as a treatment option in COVID-19 patients with AKI. The use of low-molecular-weight heparin (LMWH) in systemic anticoagulation and unfractionated heparin (UFH) in regional anticoagulation was adapted and shown to reduce the incidence of the circuit clotting observed in up to $13 \%$ of ICU patients with COVID-19 infection. These findings were later confirmed in a report by Di Mario, F. et al. [42], who tested the effectiveness of sustained low-efficiency dialysis (SLED), which is a modality of PIRRT. However, in this study, the applied anticoagulation was regional citrate anticoagulation (RCA) protocol, and it significantly lowered dialysis interruption by circuit clotting to $6.1 \%$. Moreover, the advantages of RCA over systemic heparin anticoagulation protocols have been demonstrated in a comparative study by Arnold, F. et al. [43] Taking into account these reports, we can assume that SLED with RCA protocol is the safest and most efficient way of AKI management in hemodynamically unstable COVID-19 patients.

\section{Conclusions}

Acute kidney injury is common amongst patients with SARS-CoV-2 infection, especially critically ill ones, and is without a doubt associated with higher mortality. There are numerous possible pathomechanisms which are still being investigated, but the most probable ones are direct cellular invasion, ARDS, cytokine storm and hypovolemia. Histopathological reports showed that most COVID-19 patients with AKI presented acute tubular damage, sometimes with necrosis and collapsing glomerulopathy. The most important steps that should be taken in AKI prevention are the following: minimizing the risk of hypovolemia and monitoring serum creatinine levels in the early stages of COVID-19 infection, especially in regard to the high-risk patients at an older age with diabetes mellitus, hypertension and cardiovascular diseases. However, when, despite our best efforts, COVID-19 patients are hemodynamically unstable, the safest and most efficient way of AKI management is SLED with RCA protocol. The evidence related to COVID-19 is changing dynamically and we are still in need of more research for establishing the optimal treatment of AKI in COVID-19 infection. Furthermore, physicians must be aware that patients who recover from AKI induced by SARS-CoV-2 require monitoring of their kidneys on followup, as there is rising evidence showing eGFR decreases among patients with a history of COVID-19-associated AKI [44].

Author Contributions: All authors (M.G., S.L., E.M., B.F., J.R.) were involved in the preparation of this article and J.R. revised the final version. All authors have read and agreed to the published version of the manuscript.

Funding: This research received no external funding.

Institutional Review Board Statement: Not applicable.

Informed Consent Statement: Not applicable.

Data Availability Statement: The data used in this article are sourced from materials mentioned in the References section.

Conflicts of Interest: The authors declare no conflict of interest. 


\section{References}

1. World Health Organisation (WHO). Available online: https://www.who.int/emergencies/diseases/novel-coronavirus-2019 (accessed on 4 March 2021).

2. Phan, L.T.; Nguyen, T.V.; Luong, Q.C.; Nguyen, T.V.; Nguyen, H.T.; Le, H.Q.; Nguyen, T.T.; Cao, T.M.; Pham, Q.D. Importation and Human-to-Human Transmission of a Novel Coronavirus in Vietnam. N. Engl. J. Med. 2020, 382, 872-874. [CrossRef] [PubMed]

3. Gupta, A.; Madhavan, M.V.; Sehgal, K.; Nair, N.; Mahajan, S.; Sehrawat, T.S.; Bikdeli, B.; Ahluwalia, N.; Ausiello, J.C.; Wan, E.Y. Extrapulmonary manifestations of COVID-19. Nat. Med. 2020, 26, 1017-1032. [CrossRef] [PubMed]

4. Kellum, J.A.; Lameire, N.; Aspelin, P.; Barsoum, R.S.; Burdmann, E.A.; Goldstein, S.L.; Herzog, C.A.; Joannidis, M.; Kribben, A.; Levey, A.S.; et al. Kidney disease: Improving global outcomes (KDIGO) acute kidney injury work group. KDIGO clinical practice guideline for acute kidney injury. Kidney Int. Suppl. 2012, 1-138. [CrossRef]

5. Pei, G.; Zhang, Z.; Peng, J.; Liu, L.; Zhang, C.; Yu, C.; Ma, Z.; Huang, Y.; Liu, W.; Yao, Y.; et al. Renal Involvement and Early Prognosis in Patients with COVID-19 Pneumonia. J. Am. Soc. Nephrol. 2020, 31, 1157-1165. [CrossRef] [PubMed]

6. Hirsch, J.S.; Ng, J.H.; Ross, D.W.; Sharma, P.; Shah, H.H.; Barnett, R.L. Acute kidney injury in patients hospitalized with COVID-19. Kidney Int. 2020, 98, 209-218. [CrossRef]

7. Cummings, M.J.; Baldwin, M.R.; Abrams, D.; Jacobson, S.D.; Meyer, B.J.; Balough, E.M.; Aaron, J.G.; Jan, C.; Rabbani, L.E.; Hastie, J.; et al. Epidemiology, clinical course, and outcomes of critically ill adults with COVID-19 in New York City: A prospective cohort study. Lancet 2020, 395, 1763-1770. [CrossRef]

8. Oran, D.P.; Topol, E.J. The Proportion of SARS-CoV-2 Infections That Are Asymptomatic: A Systematic Review. Ann. Intern. Med. 2021, 174, 655-662. [CrossRef]

9. Wu, Z.; Mcgoogan, J.M. Characteristics of and Important Lessons From the Coronavirus Disease 2019 (COVID-19) Outbreak in China. JAMA 2020, 323, 1239. [CrossRef] [PubMed]

10. Yang, X.; Yu, Y.; Xu, J.; Shu, H.; Xia, J.; Liu, H.; Wu, Y.; Zhang, L.; Yu, Z.; Fang, M.; et al. Clinical course and outcomes of critically ill patients with SARS-CoV-2 pneumonia in Wuhan, China: A single-centered, retrospective, observational study. Lancet Respir. Med. 2020, 8, 475-481. [CrossRef]

11. Cheng, Y.; Luo, R.; Wang, K.; Zhang, M.; Wang, Z.; Dong, L.; Li, J.; Yao, Y.; Ge, S.; Xu, G.; et al. Kidney disease is associated with in-hospital death of patients with COVID-19. Kidney Int. 2020, 97, 829-838. [CrossRef] [PubMed]

12. Chan, L.; Chaudhary, K.; Saha, A.; Chauhan, K.; Vaid, A.; Zhao, S.; Paranjpe, I.; Somani, S.; Richter, F.; Miotto, R.; et al. AKI in Hospitalized Patients with COVID-19. J. Am. Soc. Nephrol. 2021, 32, 151-160. [CrossRef] [PubMed]

13. Fisher, M.; Neugarten, J.; Bellin, E.; Yunes, M.; Stahl, L.; Johns, T.S.; Abramowitz, M.K.; Levy, R.; Kumar, N.; Mokrzycki, M.H.; et al. AKI in Hospitalized Patients with and without COVID-19: A Comparison Study. J. Am. Soc. Nephrol. 2020, 31, 2145-2157. [CrossRef]

14. Costa, R.L.D.; Sória, T.C.; Salles, E.F.; Gerecht, A.V.; Corvisier, M.F.; Menezes, M.A.D.M.; Ávila, C.D.S.; Silva, E.C.D.F.; Pereira, S.R.N.; Simvoulidis, L.F.N. Acute kidney injury in patients with Covid-19 in a Brazilian ICU: Incidence, predictors and in-hospital mortality. Braz. J. Nephrol. 2021. [CrossRef]

15. Ferlicot, S.; Jamme, M.; Gaillard, F.; Oniszczuk, J.; Couturier, A.; May, O.; Grünenwald, A.; Sannier, A.; Moktefi, A.; Le Monnier, O.; et al. The spectrum of kidney biopsies in hospitalized patients with COVID-19, acute kidney injury, and/or proteinuria. Nephrol. Dial. Transplant. 2021. [CrossRef]

16. Behzad, S.; Aghaghazvini, L.; Radmard, A.R.; Gholamrezanezhad, A. Extrapulmonary manifestations of COVID-19: Radiologic and clinical overview. Clin. Imaging 2020, 66, 35-41. [CrossRef]

17. Zhou, P.; Yang, X.L.; Wang, X.G.; Hu, B.; Zhang, L.; Zhang, W.; Si, H.R.; Zhu, Y.; Li, B.; Huang, C.L.; et al. A pneumonia outbreak associated with a new coronavirus of probable bat origin. Nature 2020, 579, 270-273. [CrossRef]

18. Hoffmann, M.; Kleine-Weber, H.; Schroeder, S.; Krüger, N.; Herrler, T.; Erichsen, S.; Schiergens, T.S.; Herrler, G.; Wu, N.-H.; Nitsche, A.; et al. SARS-CoV-2 Cell Entry Depends on ACE2 and TMPRSS2 and Is Blocked by a Clinically Proven Protease Inhibitor. Cell 2020, 181, 271-280. [CrossRef]

19. Walls, A.C.; Park, Y.-J.; Tortorici, M.A.; Wall, A.; Mcguire, A.T.; Veesler, D. Structure, Function, and Antigenicity of the SARS-CoV-2 Spike Glycoprotein. Cell 2020, 181, 281-292.e6. [CrossRef]

20. Khan, S.; Chen, L.; Yang, C.-R.; Raghuram, V.; Khundmiri, S.J.; Knepper, M.A. Does SARS-CoV-2 Infect the Kidney? J. Am. Soc. Nephrol. 2020, 31, 2746-2748. [CrossRef]

21. Rahman, N.; Basharat, Z.; Yousuf, M.; Castaldo, G.; Rastrelli, L.; Khan, H. Virtual Screening of Natural Products against Type II Transmembrane Serine Protease (TMPRSS2), the Priming Agent of Coronavirus 2 (SARS-CoV-2). Molecules 2020, $25,2271$. [CrossRef]

22. Perlman, S.; Netland, J. Coronaviruses post-SARS: Update on replication and pathogenesis. Nat. Rev. Microbiol. 2009, 7, 439-450. [CrossRef]

23. Braun, F.; Lütgehetmann, M.; Pfefferle, S.; Wong, N.M.; Carsten, A.; Lindenmeyer, T.M.; Nörz, D.; Heinrich, F.; Meißner, K.; Wichmann, D.; et al. SARS-CoV-2 renal tropism associates with acute kidney injury. Lancet 2020, 396, 597-598. [CrossRef]

24. Ronco, C.; Reis, T.; Husain-Syed, F. Management of acute kidney injury in patients with COVID-19. Lancet Respir. Med. 2020, 8, 738-742. [CrossRef] 
25. Ahmed, A.R.; Ebad, C.A.; Stoneman, S.; Satti, M.M.; Conlon, P.J. Kidney injury in COVID-19. World J. Nephrol. 2020, 9, 18-32. [CrossRef]

26. Sharma, P.; Uppal, N.N.; Wanchoo, R.; Shah, H.H.; Yang, Y.; Parikh, R.; Khanin, Y.; Madireddy, V.; Larsen, C.P.; Jhaveri, K.D.; et al. COVID-19-Associated Kidney Injury: A Case Series of Kidney Biopsy Findings. J. Am. Soc. Nephrol. 2020, 31, $1948-1958$. [CrossRef]

27. Pan, X.-W.; Xu, D.; Zhang, H.; Zhou, W.; Wang, L.-H.; Cui, X.-G. Identification of a potential mechanism of acute kidney injury during the COVID-19 outbreak: A study based on single-cell transcriptome analysis. Intensive Care Med. 2020, 46, 1114-1116. [CrossRef]

28. Ronco, C.; Reis, T. Kidney involvement in COVID-19 and rationale for extracorporeal therapies. Nat. Rev. Nephrol. 2020, 16, 308-310. [CrossRef]

29. D'Agati, V.D.; Kaskel, F.J.; Falk, R.J. Focal Segmental Glomerulosclerosis. N. Engl. J. Med. 2011, 365, 2398-2411. [CrossRef]

30. Kissling, S.; Rotman, S.; Gerber, C.; Halfon, M.; Lamoth, F.; Comte, D.; Lhopitallier, L.; Sadallah, S.; Fakhouri, F. Collapsing glomerulopathy in a COVID-19 patient. Kidney Int. 2020, 98, 228-231. [CrossRef] [PubMed]

31. Peleg, Y.; Kudose, S.; D’Agati, V.; Siddall, E.; Ahmad, S.; Nickolas, T.; Kisselev, S.; Gharavi, A.; Canetta, P. Acute Kidney Injury Due to Collapsing Glomerulopathy Following COVID-19 Infection. Kidney Int. Rep. 2020, 5, 940-945. [CrossRef]

32. Santoriello, D.; Khairallah, P.; Bomback, A.S.; Xu, K.; Kudose, S.; Batal, I.; Barasch, J.; Radhakrishnan, J.; D'Agati, V.; Markowitz, G. Postmortem Kidney Pathology Findings in Patients with COVID-19. J. Am. Soc. Nephrol. 2020, 31, 2158-2167. [CrossRef] [PubMed]

33. Farkash, E.A.; Wilson, A.M.; Jentzen, J.M. Ultrastructural Evidence for Direct Renal Infection with SARS-CoV-2. J. Am. Soc. Nephrol. 2020, 31, 1683-1687. [CrossRef] [PubMed]

34. Li, Z.; Wu, M.; Yao, J.; Guo, J.; Liao, X.; Song, S.; Yan, J. Caution on Kidney Dysfunctions of COVID-19 Patients. SSRN Electron. J. 2020. [CrossRef]

35. Richardson, S.; Hirsch, J.S.; Narasimhan, M.; Crawford, J.M.; Mcginn, T.; Davidson, K.W.; Barnaby, D.P.; Becker, L.B.; Chelico, J.D.; Cohen, S.L.; et al. Presenting Characteristics, Comorbidities, and Outcomes Among 5700 Patients Hospitalized With COVID-19 in the New York City Area. JAMA 2020, 323, 2052. [CrossRef]

36. Henry, B.M.; Lippi, G. Chronic kidney disease is associated with severe coronavirus disease 2019 (COVID-19) infection. Int. Urol. Nephrol. 2020, 52, 1193-1194. [CrossRef]

37. Morales, D.R.; Conover, M.M.; You, S.C.; Pratt, N.; Kostka, K.; Duarte-Salles, T.; Fernández-Bertolín, S.; Aragón, M.; Duvall, S.L.; Lynch, K.; et al. Renin-angiotensin system blockers and susceptibility to COVID-19: An international, open science, cohort analysis. Lancet Digit. Health 2021, 3, e98-e114. [CrossRef]

38. European Society of Cardiology. Position Statement of the ESC Council on Hypertension on ACEI-Inhibitors and Angiotensin Receptor Blockers. 2020. Available online: https://www.escardio.org/Councils/Council-on-Hypertension-(CHT)/News/ position-statement-of-the-esc-council-on-hypertension-on-ace-inhibitors-and-ang (accessed on 1 June 2020).

39. Nadim, M.K.; Forni, L.G.; Mehta, R.L.; Connor, M.J.; Liu, K.D.; Ostermann, M.; Rimmelé, T.; Zarbock, A.; Bell, S.; Bihorac, A.; et al. COVID-19-associated acute kidney injury: Consensus report of the 25th Acute Disease Quality Initiative (ADQI) Workgroup. Nat. Rev. Nephrol. 2020. [CrossRef]

40. Helms, J.; Tacquard, C.; Severac, F.; Leonard-Lorant, I.; Ohana, M.; Delabranche, X.; Merdji, H.; Clere-Jehl, R.; Schenck, M.; Fagot Gandet, F.; et al. High risk of thrombosis in patients with severe SARS-CoV-2 infection: A multicenter prospective cohort study. Intensive Care Med. 2020, 46, 1089-1098. [CrossRef]

41. Ramirez-Sandoval, J.C.; Gaytan-Arocha, J.E.; Xolalpa-Chávez, P.; Mejia-Vilet, J.M.; Arvizu-Hernandez, M.; Rivero-Sigarroa, E.; Torruco-Sotelo, C.; Correa-Rotter, R.; Vega-Vega, O. Prolonged Intermittent Renal Replacement Therapy for Acute Kidney Injury in COVID-19 Patients with Acute Respiratory Distress Syndrome. Blood Purif. 2020, 1-9. [CrossRef]

42. Di Mario, F.; Regolisti, G.; Di Maria, A.; Parmigiani, A.; Benigno, G.D.; Picetti, E.; Barbagallo, M.; Greco, P.; Maccari, C.; Fiaccadori, E. Sustained low-efficiency dialysis with regional citrate anticoagulation in critically ill patients with COVID-19 associated AKI: A pilot study. J. Crit. Care 2021, 63, 22-25. [CrossRef]

43. Arnold, F.; Westermann, L.; Rieg, S.; Neumann-Haefelin, E.; Biever, P.M.; Walz, G.; Kalbhenn, J.; Tanriver, Y. Comparison of different anticoagulation strategies for renal replacement therapy in critically ill patients with COVID-19: A cohort study. BMC Nephrol. 2020, 21. [CrossRef]

44. Nugent, J.; Aklilu, A.; Yamamoto, Y.; Simonov, M.; Li, F.; Biswas, A.; Ghazi, L.; Greenberg, J.H.; Mansour, S.G.; Moledina, D.G.; et al. Assessment of Acute Kidney Injury and Longitudinal Kidney Function after Hospital Discharge among Patients with and without COVID-19. JAMA Netw. Open 2021, 4, e211095. [CrossRef] [PubMed] 